\title{
Finger clubbing caused by herbal tea
}

\author{
SAIFUDIN RASHIQ MB FRCPC ${ }^{*}$, NEIL E BROWN MD FRCPC ${ }^{\dagger}$, RICHARD N FEDORAK MD FRCPC ${ }^{\ddagger}$ \\ ${ }^{*}$ Department of Anaesthesia, and Divisions of ${ }^{\dagger}$ Pulmonary Medicine and ${ }^{\ddagger}$ Gastroenterology, \\ Department of Medicine, University of Alberta, Edmonton, Alberta
}

S RASHIQ, NE BROWN, RN FEDORAK. Finger clubbing caused by herbal tea. Can Respir J 1996;3(4):269-271.

Clubbing of the fingers is often taken to be a sign of serious illness. Its discovery, particularly if there are associated symptoms in the cardiovascular, respiratory or gastrointestinal systems, usually leads to exhaustive investigation. A case is presented in which the etiology of clubbing was found only when a new history of heavy ingestion of herbal tea was obtained, extensive work-up having previously been unhelpful. Other cases appearing in the English-language literature are cited, some universal etiological associations are described, and an attempt is made to explain the phenomenon, based on a recent theory of the cause of clubbing.

Key Words: Digital clubbing, Herbal remedies, Laxatives, Senna

\section{Hippocratisme digital attribuable à la tisane}

RÉSUMÉ : On considère souvent l'hippocratisme digital comme étant le signe d'une affection sévère. Sa découverte, surtout si elle s'accompagne de symptômes affectant les systèmes cardio-vasculaire, respiratoire ou gastro-intestinal, conduit généralement à une investigation exhaustive. Un cas est présenté dans lequel l'étiologie de l'hippocratisme a été mise en évidence seulement après qu'une histoire récente d'ingestion intensive de tisane ait été obtenue et que les examens approfondis pratiqués précédemment n'aient pas permis de poser un diagnostic. D'autres cas décrits dans les articles médicaux de langue anglaise sont cités, quelques associations étiologiques universelles sont décrites, et l'on tente d'expliquer ce phénomène, sur la base d'une théorie récente de la cause de l'hippocratisme digital.
A 47-year-old woman was admitted to hospital for investigation of abdominal pain and finger clubbing. She gave a 10-year history of constant, severe pain in all areas of the abdomen, unrelieved by any posture, dietary manipulation or any therapeutic agent. There was no associated vomiting, jaundice, bloating or flatus. She reported long-standing difficulty in defecation since youth. Her clubbing had been present for seven years, but had become more severe during the past three. She complained of a constant burning in the fingertips and difficulty in performing fine motor tasks. She was married and had three healthy teenaged children. She smoked three cigarettes a day, but took no alcohol. Past medical history was positive for low back pain six years previously. She had undergone a laminectomy at that time.

The patient had undergone numerous investigations to determine the cause of her abdominal pain. These included full hematological, biochemical, endocrine and immunological bloodwork, upper and lower gastrointestinal endoscopy with biopsies on multiple occasions, contrast imaging of the entire gastrointestinal tract, computed tomography of the

Correspondence and reprints: Dr Neil E Brown, Department of Medicine, 2E3.26 Walter Mackenzie Health Sciences Centre, Edmonton, Alberta T6G 2B7. Telephone 403-492-6448, fax 403-492-3340, e-mail neil.brown@ ualberta.ca 
TABLE 1

Reported cases of finger clubbing secondary to sennoside abuse

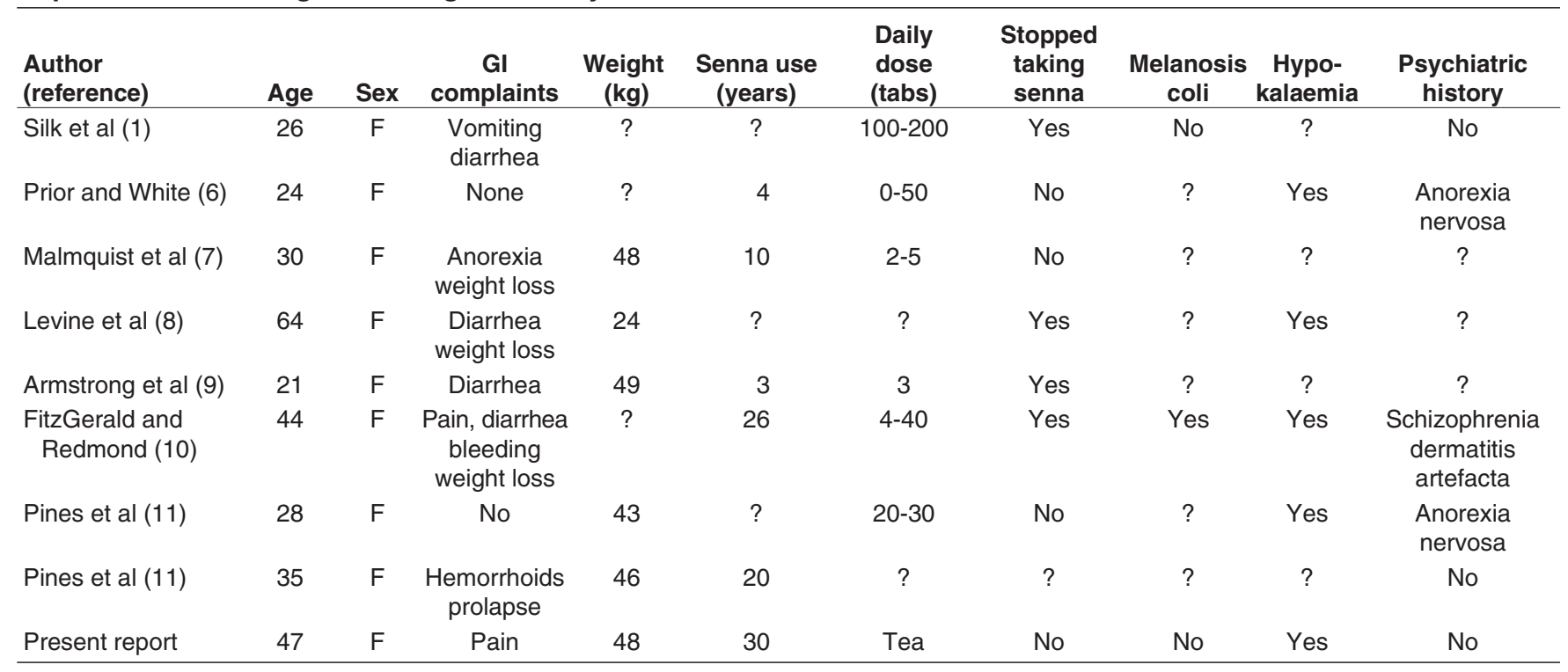

? Data not given; Gl Gastrointestinal

abdomen and pelvis, magnetic resonance imaging of the liver, malabsorption studies, electrocardiogram and urine culture. Positive findings were a benign colonic polyp and mild nonspecific ileitis in one of several biopsy specimens. The latter finding was not, in isolation, felt to be diagnostic of inflammatory bowel disease or any other discrete disease entity. Since the discovery of her clubbing, she had been seen by a number of medical specialists, including gastroenterologists and pulmonologists, and she had had serial chest x-rays, echocardiography, fibreoptic bronchoscopy and blood cultures, all of which were negative. Her medications on admission were diazepam $40 \mathrm{mg}$ daily, hydrochlorothiazide $25 \mathrm{mg}$ daily and domperidone $40 \mathrm{mg}$ daily. In addition, she had been given frequent intramuscular injections of meperidine $50 \mathrm{mg}$ at a peripheral hospital in the days leading up to transfer.

Physical examination showed her to be $165 \mathrm{~cm}$ tall and to weigh $48 \mathrm{~kg}$. Her cardiovascular system showed no abnormality. Her lung fields were clear. There was no adenopathy, and neurological examination was normal. Palpation of the abdomen resulted in great discomfort, although it was not possible to determine whether this was particularly so in any given area. There was no hepatosplenomegaly or other mass. Rectal examination was normal. Laboratory investigations consisted of a blood count with differential, chemical profile, thyroid stimulating hormone, clotting studies and liver function tests, all of which were normal. A psychiatrist failed to find evidence for a psychogenic basis for the symptoms. An exploratory laparotomy, performed as a diagnostic procedure of last resort, failed to yield a diagnosis.

During yet another consultative interview, the patient admitted to having used a herbal laxative tea preparation for more than 30 years. She believed this to be a nonpharmacological means of aiding satisfactory bowel actions, and had not thought to mention it when asked about her medication use previously. The compound (Bekunis) contains $2.5 \%$ Tin- velly Senna (sennosides A and B) by weight. In the absence of any other apparent cause, a putative diagnosis of clubbing secondary to senna abuse was made. Eleven months later, she had reduced the quantity of this preparation that she ingests, but was unable to discontinue it entirely. Her clubbing persists, as do her symptoms.

\section{DISCUSSION}

Clubbing secondary to sennoside abuse was first reported in 1975 (1). Several others have reported similar findings, but in each case the patients concerned were using pharmacological preparations of senna to huge excess (Table 1). We believe that this is the first report of this phenomenon being due to a herbal compound. Our patient's circumstances were not dissimilar from those in other reports: all are females, with protracted histories of abdominal complaints not amenable to sophisticated diagnostic techniques. In each case, the discovery of clubbing caused medical attendants to intensify the search for an organic diagnosis. If sennosides are stopped, the clubbing disappears, but in many cases, the desire to continue the herbal compound is overwhelming.

The mechanism by which clubbing might result from sennoside abuse is unclear. Dickinson (2) has proposed a unifying theory of the etiology of clubbing, in which the local tissue hypertrophy results from the deposition in the fingertips of megakaryocytes (MK) and platelet clumps. MK are abundant in venous blood, but are normally fragmented by the passage of blood through the pulmonary capillaries. They are postulated to release platelet-derived growth factor (PDGF) in high concentrations when they become trapped in the capillaries of the fingers and toes. It is hypothesized that the heterogeneous group of diseases that are associated with clubbing facilitate the arrival of increased numbers of MK and platelets at the distal capillaries, by creating either a route for venous blood to bypass the pulmonary vascular bed, such 
as in cyanotic heart disease with right-to-left shunting, or a nidus of platelet clumps, which can then break off and flow distally, as in the case of bacterial endocarditis.

Anthraquinone laxatives exert their therapeutic effects by an unknown mechanism (3). If Dickinson's hypothesis is true, one is forced to consider how these drugs might facilitate an increased number of platelets and MK in the capillaries of the fingertips. Possible mechanisms include an increased production of MK, impairment of the MK degradation system in the lung, shunting of blood past the pulmonary capillaries, an increase in platelet adhesiveness or an increased production of PDGF by MK. Anthraquinones are known to cause an increase in capillary diameter in enterocytes (4), and increased concentrations of vasodilatory mediators, including prostaglandin $\mathrm{E}_{2}$ and serotonin, are demonstrable in enterocytes that have been exposed in vivo to high concentrations of these drugs (3). Perhaps an analogous situation occurs in the pulmonary capillaries at the same time. Enterocyte platelet activating factor levels were not raised after chronic senna exposure in one rat study, but systemic levels were not measured (5). There are no data regarding the direct or indirect effects of the anthraquinones on platelet function or vascular tone outside the gastrointestinal tract.

Clubbing of the fingers remains a sign associated, in the vast majority of cases, with organic disease. Only when sinister pathology has been carefully excluded can the search for more obscure etiologies be undertaken. This case served to remind us of the fundamental importance of meticulous history-taking in cases of diagnostic difficulty.

\section{REFERENCES}

1. Silk DBA, Gibson JA, Murray CRH. Reversible finger clubbing in a case of purgative abuse. Gastroenterology 1975;68:790-4.

2. Dickinson CJ. The aetiology of clubbing and hypertrophic osteoarthropathy. Eur J Clin Invest 1993;23:330-8.

3. Geboes K, Spiessens C, Nijs G, de Witte P. Anthranoids and the mucosal immune system of the colon. Pharmacology 1993;47 (Suppl 1):49-57.

4. Mengs V, Rudolph RL. Light and electron microscopic changes in the colon of the guinea pig after treatment with anthranoid and non-anthranoid laxatives. Pharmacology 1993;47(Suppl 1):172-7.

5. Capasso F, Izzo AA, Mascolo N, Autore G, Di Carlo G. Effect of senna is not mediated by platelet-activating factor. Pharmacology 1993;47(Suppl 1):58-63.

6. Prior J, White I. Tetany and clubbing in patient who ingested large quantities of senna. Lancet 1978;ii:947. (Lett)

7. Malmquist J, Ericsson B, Hulten-Nosslin M-B, Jeppsson J-O, Ljungberg O. Finger clubbing and aspartylglucosamine excretion in a laxative-abusing patient. Postgrad Med J 1980;56:862-4.

8. Levine D, Goode AW, Wingate DL. Purgative abuse associated with reversible cachexia, hypogammaglobulinaemia, and finger clubbing. Lancet 1981;i:919.

9. Armstrong RD, Crisp AJ, Grahame R, Woolf DL. Hypertrophic osteoarthropathy and purgative abuse. BMJ 1981;282:1836.

10. Fitzgerald O, Redmond J. Anthraquinone-induced clubbing associated with laxative abuse. Ir J Med Sci 1983;152:246-7.

11. Pines A, Olchovsky D, Bregman J, Kaplinski N, Frankl O. Finger clubbing associated with laxative abuse. South Med J 1983;76:1071-2. 


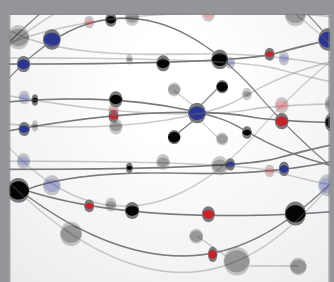

The Scientific World Journal
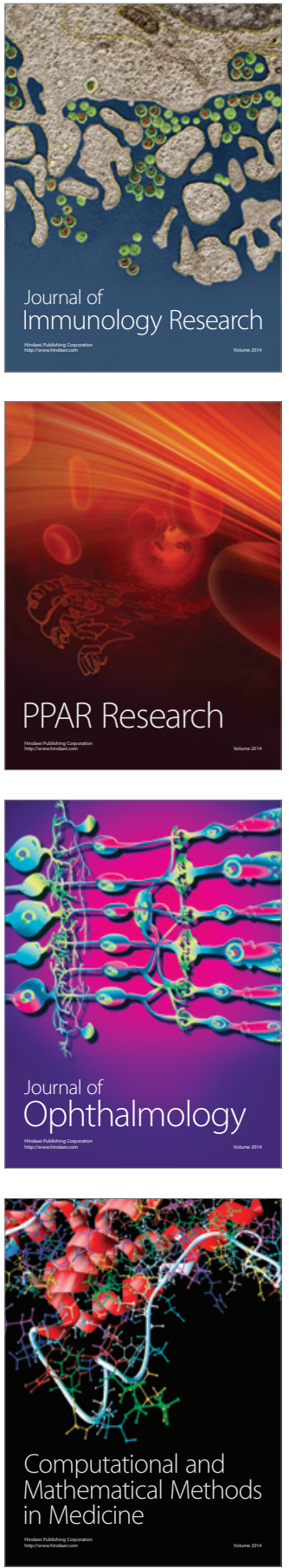

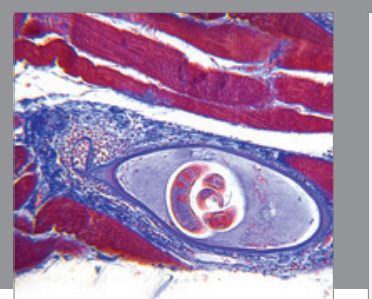

Gastroenterology Research and Practice

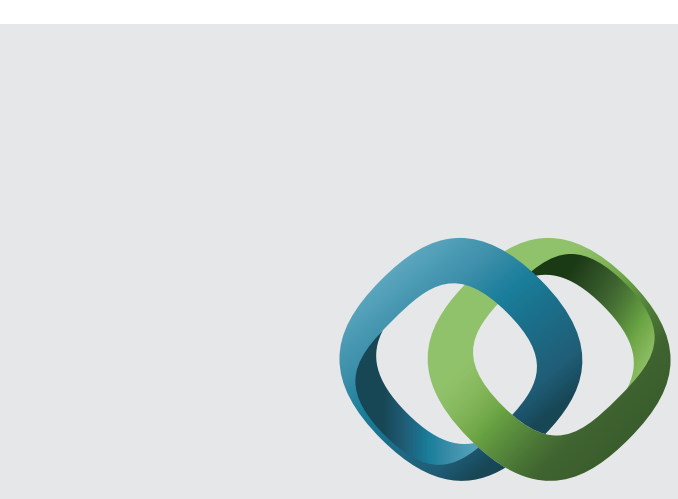

\section{Hindawi}

Submit your manuscripts at

http://www.hindawi.com
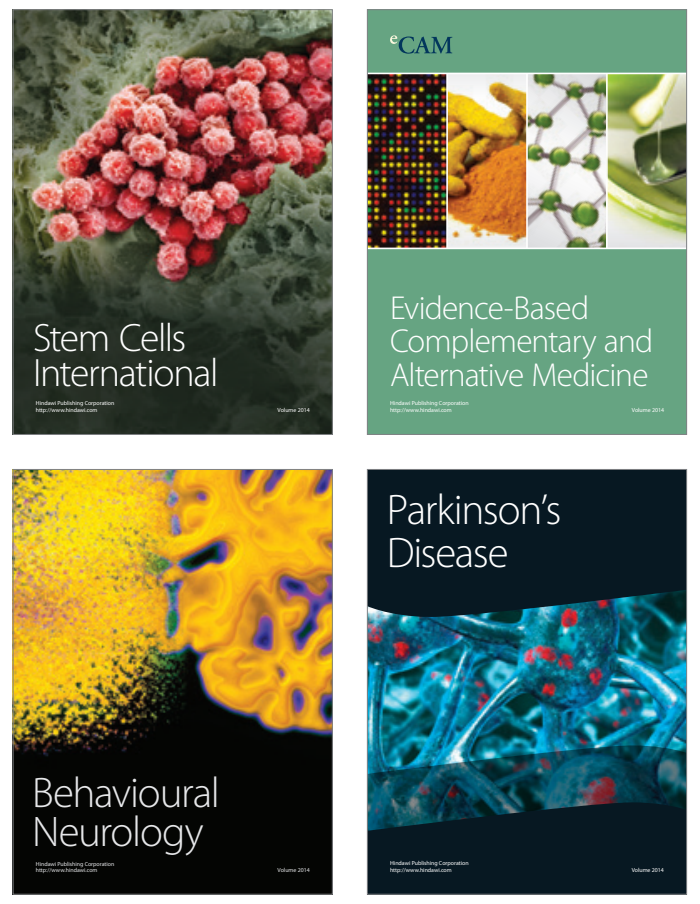
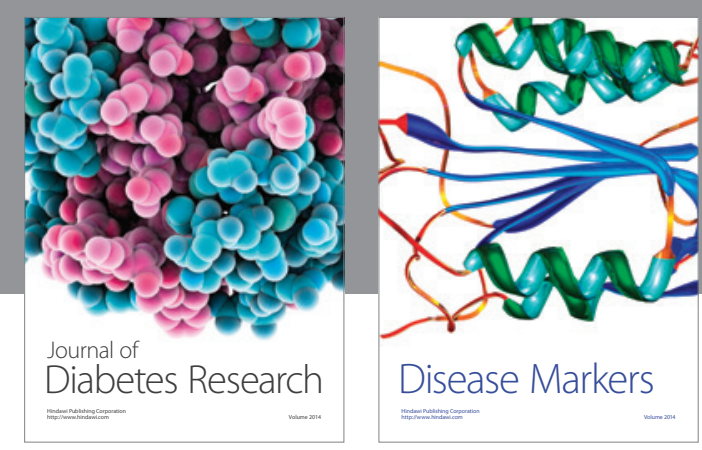

Disease Markers
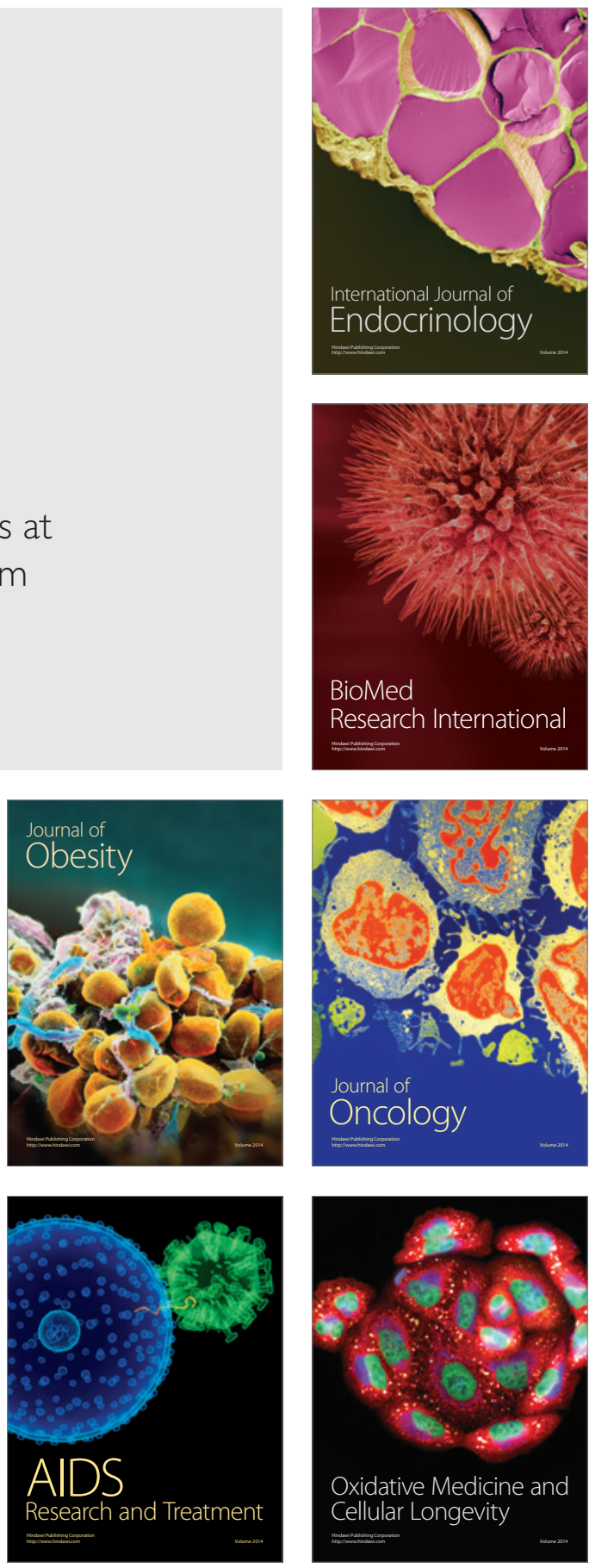